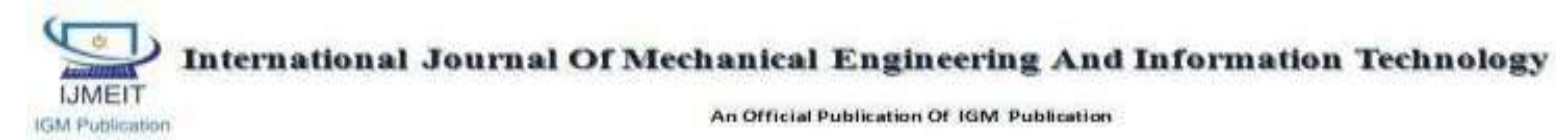

Index Copernicus Value-63.45

\title{
Transient State Analysis of Variation in Thermal Contact Area in Fin And Tube Heat Exchanger
}

\section{Authors \\ Vaibhav Kumar', R.M. Sarviya ${ }^{2}$}

${ }^{1}$ PG Student, Mechanical Engineering department, Maulana Azad National Institute of Technology, Bhopal

${ }^{2}$ Professor, Mechanical Engineering department, Maulana Azad National Institute of Technology, Bhopal

\begin{abstract}
Present work aims to analyze the significance of thermal contact area between fins and tubes in a heat exchanger. The heat exchanger type selected for the detailed study is a liquid-gas fin and tube heat exchanger. Four different cases based on a variable degree of thermal contact between fins and tubes are investigated. Case-I with 100\% thermal contact area between the fin and tube is set as a reference to casesII, III, and IV with a thermal contact area of approximately 80\%, 60\%, and 40\% respectively. Threedimensional (3D) modelling is done for the heat exchanger and is investigated for transient state heat transfer. In order to develop a simplified model with desired physical phenomena, only gas-side flow over the fin is simulated in the present study and the temperature inside the tube is kept to be constant as if phase change operation is taking place inside the tube. Thus only the temperature variations in the fin domain are studied as well as the heat flux for different cases. The results obtained from the detailed analysis are useful to examine the impact of the degree of thermal contact and to compare the performance of heat exchanger design in different cases. Comparative analysis indicates a significant influence of the degree of the thermal contact area between fin and tube on the overall performance. Case-I is found to have higher heat flux in comparison with the cases- I,II,III and IV which is due to the fact that there is minimal thermal resistance in the direction of flow and as a result of this the temperature drop from the tube to the fin is also the least among all the cases. The temperature and heat flux values thus obtained are compared side by side to have a deeper understanding of the difference among all the four cases.

Keywords-ANSYS 15.0, Fin and tube Heat Exchanger, Heat Flux, Thermal contact area.
\end{abstract}

\section{INTRODUCTION}

Finned-tube heat exchangers, or coils, consist of mechanically or hydraulically expanded round tubes in a block of parallel continuous fins. The plates are mechanically bonded onto the outer surface of the tubes by various means such as by bolted or welded joints. The heat exchange takes place between the flowing fluids in the tube and the surrounding medium (may be gaseous or liquid). The exchange can take place in either direction depending upon the temperatures the fluids in tube and the gas domains. The Finned-tube heat exchangers are a common sight in various domestic and industrial applications and are used widely. The most widely used tube material is steel followed by copper alloys such as 90-10 cupronickel and 70-30 cupronickel.
The nickel added to the copper adds to the strength as wells the corrosion resistance. Plate fin-and-tube heat exchangers of plain fin pattern are frequently employed in the process and HVAC\&R (Heating, Ventilating, air conditioning, and refrigeration) industries. The plain plate fin configuration is the most widely accepted fin pattern owing to its simplicity, sturdiness and versatility in application. The plain fin-tube heat exchangers usually consist of mechanically or hydraulically expanded round tubes in a block of parallel continuous fins and, depending on the application, the heat exchangers can be created with one or more than one rows. During the past few decades many efforts have been committed to heat transfer and friction characteristics of plate fin-and tube heat exchangers. 
Among the entire extended fin surfaces, plain fin represents the most simplest geometry.

Cristoph et al.[1] performed the analysis by sectioning and microscopic examination and came to the conclusion that under typical operating conditions that resistance due to poor fin-to-tube mechanical contact can be $12 \%$ higher than the airside resistance. They further concluded that construction with aluminum brazing technique can further eliminate this contact resistance. In addition to that they also did the Comparison of the standard wavy fin and a flat fin showed the wavy fin to have $19 \%$ higher heat transfer coefficient and 10\% higher pressure drop at the design Reynolds number.

Jeong et al.[2] investigated the thermal contact conductances using the experimental and numerical method in the fin and tube heat exchangers with 7 $\mathrm{mm}$ tubes. It has been discovered that the factors such as fin type, manufacturing type of the tube and etc. have a great effect on the thermal contact resistance in fin-tube heat exchanger with $7 \mathrm{~mm}$ tube. They concluded that the thermal contact resistance reduces with the increase of the tube expansion ratio and the number of fin, and the thermal contact conductance in the case of wide slit fin is greater than that of normal slit fin and that in the case of plate fin is largest of all fin types. They further concluded that he thermal contact conductance in the case with welded tube is better than that with drawn tube and that in the case without hydrophilic coating is superior than that with hydrophilic coating. The portions of the thermal contact resistance are about $15-25 \%$ in cases of the fin-tube heat exchanger with $7 \mathrm{~mm}$ tube, and it implies that the thermal contact resistance must not be overlooked in the process of design of the fin-tube heat exchanger.

J.W. Sheffield, R.A. Wood, H.J. Sauer[3] did Experimental investigation of thermal conductance of finned tube contacts and formulated the method to find out thermal contact resistance using measurable parameters like fin spacing, fin thickness tube hardness, and tube diameter as prediction parameters. They examined and tested thirty-one coils in a vacuum chamber and developed a correlation that predicts the thermal contact conductance.

D. Coetzee et al.[4] did Analysis and measurement of contact and gap resistances in extruded bimetallic finned tubes using a three resistance method. The procedure of three- resistance method is predominantly accurate in the case of good quality tubes in which the contact resistance is difficult to be measured by most of the other methods. It additionally tends to highlight resistances in poor quality tubes.

Chang Nyung Kim et al.[5] performed a study on the correlation between the thermal contact conductance and effective factors in fin-tube heat exchangers with $9.52 \mathrm{~mm}$ tube.

Jannick et al.[6] showed that brazed heat exchanger can get an average capacity improvement of $1.5 \%$ in comparison to the mechanically bonded finned tube heat exchanger. The perfect contact between the tube and the fin can reduce the contact resistance and improve the heat transfer performance.

A.I. ElSherbini et al.[7] performed an Experimental investigation of thermal contact resistance in plainfin-and-tube evaporators with collarless fins. The test coils used have aluminum fins and tubes with no fin-collars. Two coils were examined: first one in the as-manufactured condition, and the other one with brazed fin-tube joints-providing an intimate, metallurgical, bond between fins and tubes. Both heat exchangers were examined under dry and frosting conditions. The outcome under dry setting showed the contact resistance to be very high, due to the small contact area caused by the nonexistence of fin collars. The measured contact resistance was as high as the total air-side resistance and Brazing the fins caused the resistance to drop by $50 \%$ of its unbrazed value.

\section{PROBLEM IDENTIFICATION}

During manufacturing the uneven fit of fins around the circumference of tube joining fins with tubes may leave air gaps and non-uniform joints which leads to the variable thermal contact area between the fin and tube. This variation in the thermal contact area between the fin and tube can be crucial in an individual fin performance; hence, 
investigation to reveal its impact on the overall performance should be performed. Improper contact between fin and tube generates resistance which is difficult to estimate and influences the heat transfer between fin and tube of the heat exchanger. The contribution of thermal contact resistance to the total thermal resistance in heat exchangers is not always negligible especially when fin and tube are bonded mechanically (like welding and soldering based on material and application). Due to the extensive use of mechanically assembled fin $\&$ tube heat exchangers refrigeration and domestic airconditioning systems, there is a need for thorough knowledge of heat transfer and its relationship with different parameters within these heat exchanger designs.

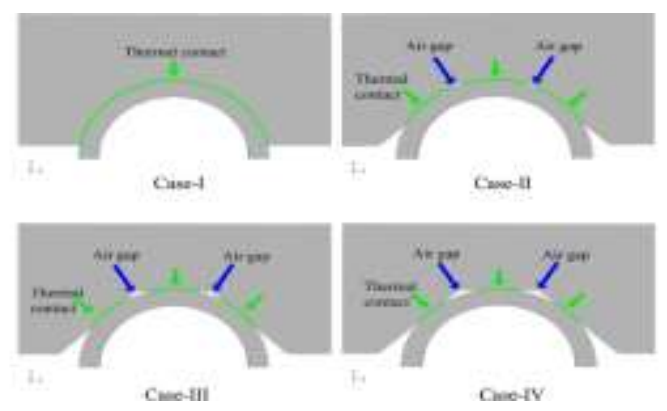

Fig.1 Geometric representation of Different cases investigated based on the variation of thermal contact area

\section{METHODOLOGY}

The methodology adopted can be described under following heads:

\subsection{Cases investigated}

The present investigation incorporates total four different cases which are summarized based on a degree of the thermal contact area i.e $100 \%, 80 \%$, $60 \%$ and $40 \%$ in a fin and tube heat exchanger design. Both the steady state and the transient state cases are studied for the variation in temperature, heat flux etc. For simplification the steady state analysis is performed first and thereafter the much more detailed transient analysis is performed which provides a deep insight into the nature of variation of heat flux and temperatures with time is all the cases.

\begin{tabular}{|c|c|c|c|c|}
\hline & CASE-I & CASE-II & CASE-III & CASE-IV \\
\hline $\begin{array}{c}\text { Thermal } \\
\text { contact area }\end{array}$ & $100 \%$ & $80 \%$ & $60 \%$ & $40 \%$ \\
\hline
\end{tabular}

\subsection{Geometry}

Fig-2 shows the schematic diagram of a single unit of fin-tube heat exchanger using the dimensions as shown in the table. The above physical dimensions and model building steps are applied to all the cases mentioned as is used as a base design. Only parameter which is varied is the thermal contact area which is the measure of the physical contact of the boundary of the outer surface of the tube and the rectangular fin or in other words the overlap area at the fin-tube interface.

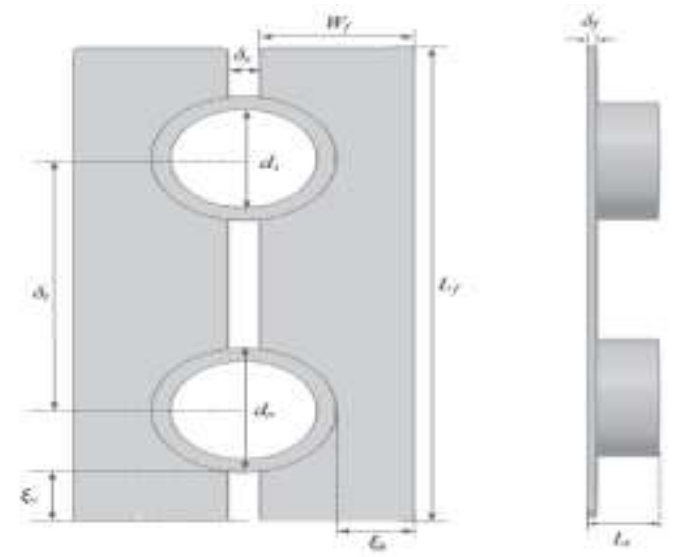

Fig.2 Schematic of single unit of a fin and tube heat exchanger

\begin{tabular}{|l|l|l|l|}
\hline Description & Symbol & Value & Unit \\
\hline Length of the fin & $\mathrm{L}_{\mathrm{f}}$ & 145.0 & $\mathrm{~mm}$ \\
\hline Width of the fin & $\mathrm{W}_{\mathrm{f}}$ & 32.0 & $\mathrm{~mm}$ \\
\hline Thickness of the fin & $\delta_{\mathrm{f}}$ & 2.0 & $\mathrm{~mm}$ \\
\hline Width of the gap between the fins & $\delta_{\mathrm{s}}$ & 7.0 & $\mathrm{~mm}$ \\
\hline Inner diameter of the tube & $\mathrm{d}_{\mathrm{i}}$ & 30.0 & $\mathrm{~mm}$ \\
\hline Outer diameter of the tube & $\mathrm{d}_{\mathrm{o}}$ & 38.0 & $\mathrm{~mm}$ \\
\hline Length of the tube (between two & $\mathrm{L}_{\mathrm{t}}$ & 15.0 & $\mathrm{~mm}$ \\
\hline Tube spacing (center to center) & $\delta_{\mathrm{t}}$ & 77.0 & $\mathrm{~mm}$ \\
\hline Tube pitch (vertical) & $\xi_{\mathrm{v}}$ & 15.0 & $\mathrm{~mm}$ \\
\hline Tube pitch (horizontal) & $\xi_{\mathrm{h}}$ & 16.0 & $\mathrm{~mm}$ \\
\hline
\end{tabular}

\begin{tabular}{|c|c|c|}
\hline $\begin{array}{c}\text { Case } \\
\text { investigated }\end{array}$ & $\begin{array}{c}\text { Thermal } \\
\text { contact area } \\
\left(\mathrm{m}^{2}\right)\end{array}$ & $\begin{array}{c}\text { Thermal contact } \\
\text { area }(\%)\end{array}$ \\
\hline I & $10.63 \times 10^{-5}$ & 100 \\
\hline II & $8.50 \times 10^{-5}$ & 80 \\
\hline III & $6.38 \times 10^{-5}$ & 60 \\
\hline IV & $4.25 \times 10^{-5}$ & 40 \\
\hline
\end{tabular}

\subsection{Material data}

The material used in the present analysis is CuNi10Fe1Mn which is commonly known as 90/10 Copper-Nickel-lron or 90/10 Cupro-nickel or Cupro-nickel 90/10. A copper-nickel alloy with an alpha phase structure. Small amounts of iron and 
manganese are added to improve corrosion resistance in high-velocity (from 1 to about $3.5 \mathrm{~m} / \mathrm{s}$ ) waters, including seawater. The alloy is relatively insensitive to stress corrosion. It has good cold- and hot-working properties and is readily weldable. The most commonly used wrought forms are plate, sheet and tube.

\begin{tabular}{|c|c|}
\hline Thermal Conductivity & $50.208 \mathrm{~W} / \mathrm{m}-$ \\
\hline Density & $8900 \mathrm{~kg} / \mathrm{m}^{3}$ \\
\hline Specific heat & $376.56 \mathrm{~J} / \mathrm{kg}-\mathrm{K}$ \\
\hline
\end{tabular}

Property values of the material of heat exchanger

\subsection{Boundary conditions}

3.4.1 Inlet boundary condition

At the inlet of the flow domain, the temperature boundary condition are given as:

$\mathrm{T}=\mathrm{T}_{\text {in }}=20^{\circ} \mathrm{C}$.

\subsubsection{Wall boundary condition}

The inner tube wall temperature is assumed to be constant and the temperature boundary condition is set as

$$
\mathrm{T}=\mathrm{T}_{\mathrm{w}}=100^{\circ} \mathrm{C} \text {. }
$$

\section{RESULTS AND DISCUSSION}

The transient state analysis is performed and the variation in the temperatures and the heat flux with respect to time in all the cases are studied and plotted on the graphs and the nature of the variation along with the possible causes are studied for the analysis performed for a step duration of 5 second. As we know that in transient state the temperature as well as the heat flux are a function of time hence investigation is performed to study the temperatures as well as heat flux at different instants and are plotted on the temperature vs time and heat flux vs time graphs.

\subsection{Comparison of Temperature distribution under transient state.}

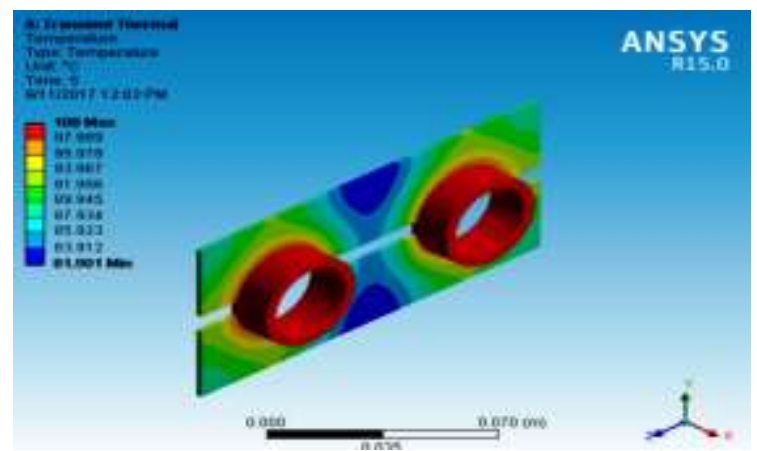

Fig.3(a)

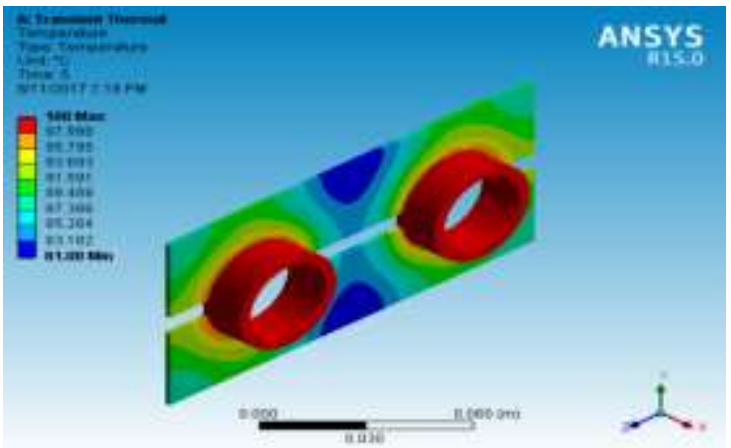

Fig.3(b)

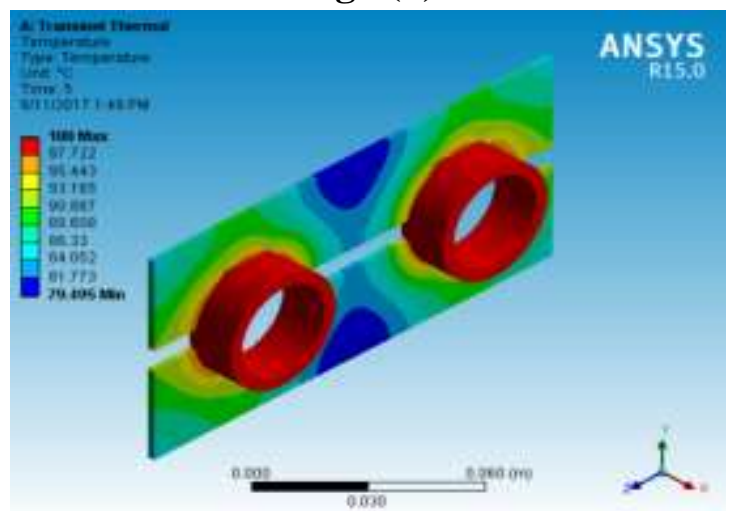

Fig.3(c)

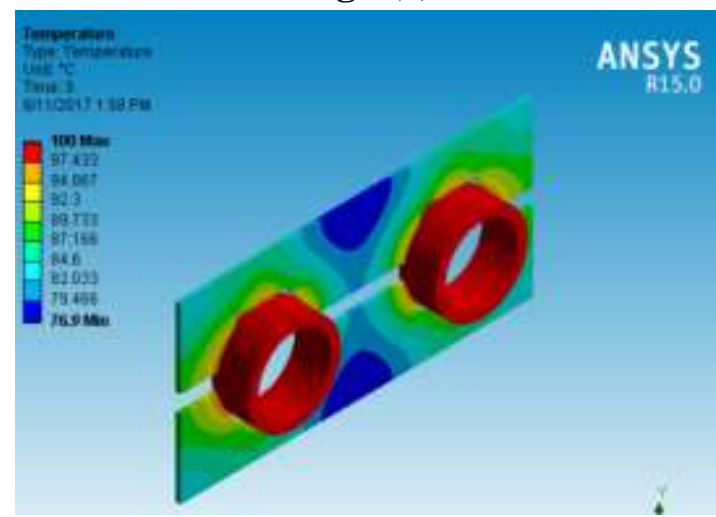

Fig.3(d)

Fig.3 Temperature field in the gas domain for - (a) case-I, (b) case-II, (c) case-III, and (d) case-IV.

\subsection{Comparison of heat flux distribution under transient state}

The analysis for heat flux distribution as well as the temperature is done for a period of $5 \mathrm{sec}$. The heat flux is found to vary at a very high rate in the initial period of about 1 second due to the high temperature gradients after which the gradients reduces thus results for heat flux variation are studied in two parts i.e between $\mathrm{t}=\mathrm{os}$ to $\mathrm{t}=1 \mathrm{~s}$ followed by $\mathrm{t}=1 \mathrm{~s}$ and $\mathrm{t}=5 \mathrm{~s}$. 


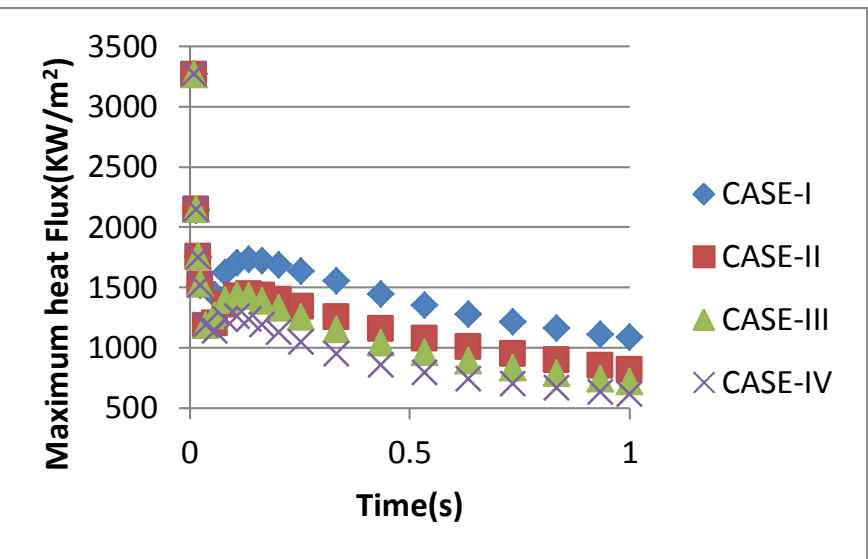

Fig.4 Comparison of heat flux between $\mathrm{t}=\mathrm{os}$ to $\mathrm{t}=1 \mathrm{~s}$.

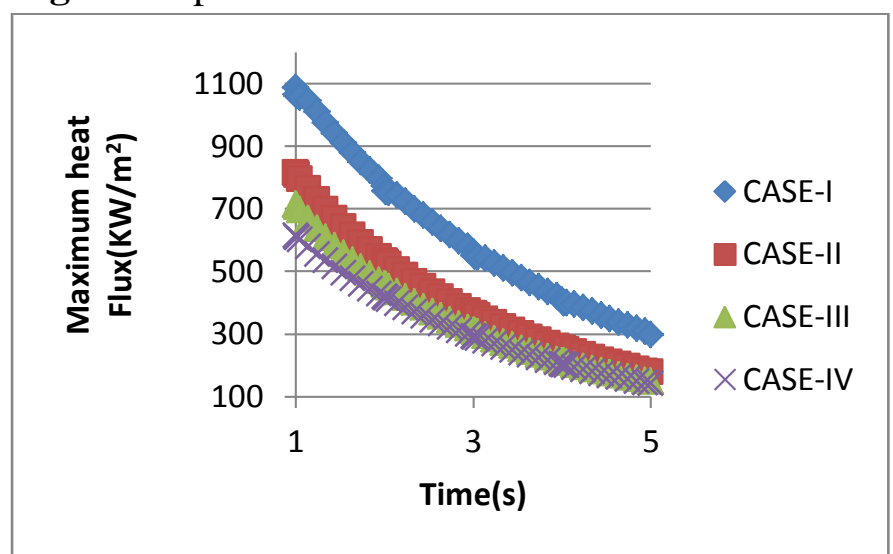

Fig.5 Comparison of heat flux between $\mathrm{t}=1 \mathrm{~s}$ to $\mathrm{t}=5 \mathrm{~s}$.

\subsection{Discussion}

As we proceed from $100 \%$ thermal contact area to $40 \%$ thermal contact area the thermal resistance in the path of fluid flow increases. Due to this increase in thermal resistance the temperature drop increases as we move from Case-I to Case-IV as can be seen in Fig.3(a),(b).(c) and (d) respectively. Although the temperature drop is seen to be marginal.

As it can be seen from the Fig-4 and Fig-5 that maximum heat flux values at the starting is very high as it is quite evident due to the temperature difference being the highest. As we know that in a thermal circuit if the temperature difference is maximum at a constant thermal resistance the heat flux is higher. This is the reason that the heat flux gradient is very high at the beginning which reduces further as the time proceeds. The heat flux gradients decreases with time at nearly $t=5 \mathrm{sec}$ because of the fact that the temperature of fin increases significantly and as the temperature of tube remains constant the temperature difference reduces significantly which causes a plunge in heat flux. Thus the main point to be noted is that the thermal contact area must be kept as high as possible which is usually limited by the mechanical constraints. Thus efforts must be made to reduce those gaps which produces hindrance in the flow of heat

\section{CONCLUSION}

Present work investigates the effect of degree of the thermal contact area between the fin and tube on the performance of a fin and tube heat exchanger. Four different cases are selected based on the degree of the thermal contact area between fin and tube and modeled to simulate the heat transfer phenomena. The results are obtained from commercial software ANSYS and are depending entirely on the preassumptions made in the study. The work done can be used as a general framework which can be modified for better understanding and modeling of the new research problem in terms of both procedure and results. The results demonstrate the effect of varying thermal contact area between fin and tube on temperature distribution and performance parameters such as overall heat flux. The degree of the thermal contact area between fin and tube is found to have a significant influence on overall heat transfer as demonstrated by the results. The maximum temperature is seen to drop slightly in both the steady state as well as the transient state analysis. This temperature drop is quite obvious as from case-I to case-IV the

thermal resistance in the path of flow is increased leading to a slight temperature drop. The heat flux on the other hand decreases in case of transient heat transfer from case-I to case-IV due to the fact that thermal resistance increases in the heat flow direction. In view of both thermal and mechanical performance, case-I is concluded to be more efficient; however case-II with $80 \%$ thermal contact area considered as a promising design which can be used in extended optimization studies of fin and tube heat exchanger for optimal performance. The study may assist researchers and heat exchanger design manufacturers by providing insights into the physical phenomena with different thermal contact area at the fin and tube interface and hence direct the optimization studies on fin-tube heat exchanger designs in order to meet the requirements on an industrial scale. 


\section{REFERENCES}

1. R.E. Critoph, M.K. Holland, L. Turner, Contact resistance in air-cooled plate fintube air-conditioning condensers, Int. J. Refrig. 9 (1996) 400-406.

2. J. Jeong, C.N. Kim, B. Youn, Y.S. Kim, $A$ study of the correlation between the thermal contact conductance and effective factors in fin-tube heat exchangers with $9.52 \mathrm{~mm}$ tube, Int. J. Heat Fluid Flow 25 (2004) 1006-1014.

3. J.W. Sheffield, R.A. Wood, H.J. Sauer, Experimental investigation of thermal conductance of finned tube contacts, Exp. Therm. Fluid Sci. 2 (1989) 107-121.

4. D. Coetzee, D.G. Kröger, Analysis and measurement of contact and gap resistances in extruded bi-metallic finned tubes, J. Heat Recov. Syst. 6 (6) (1986) 503-513.

5. Chang Nyung Kim, Jin Jeong, Baek Youn, Evaluation of thermal contact conductance using a new experimental-numerical method in fin-tube heat exchangers International Journal of Refrigeration, 2003, pp. 900-908.

6. P. Jannick, C. Meurer, H.W. Swidersky, Potential of brazed finned tube heat exchangers in comparison to mechanical produced finned tube heat exchangers, in: International Refrigeration and Air Conditioning Conference, 2002 (paper-572).

7. A.I. ElSherbini et al., Experimental investigation of thermal contact resistance in plain-fin-and-tube evaporators with collarless fins, International Journal of Refrigeration 26(5):527-536 • August 2003. 